\title{
Complex function of magnesium in blood clot formation and lysis
}

\author{
JERZY JANKUN $N^{1,2,3}$, EWA SKRZYPCZAK-JANKUN ${ }^{l}$, BOGUSEAW LIPINSKI ${ }^{4}$ \\ ${ }^{1}$ Urology Research Center, Department of Urology, The University of Toledo - Health Science Campus, Toledo, USA \\ ${ }^{2}$ Clinical Nutrition, Medical University of Gdańsk, Poland \\ ${ }^{3}$ Protein Research Chair, Biochemistry Department, College of Sciences, King Saud University, Riyadh, Saudi Arabia \\ ${ }^{4}$ Joslin Diabetes Center, Harvard Medical School, Boston, USA
}

\begin{abstract}
Magnesium salts alone or mixed with other minerals and vitamins are commonly used as dietary supplements. Also, magnesium is infused intra-operatively in a variety of surgeries. Magnesium is one of the most plentiful intracellular divalent cation and is a cofactor in approximately 300 enzymatic reactions. Magnesium is considered safe; however, there are some reports on its health risk when overdosed. It has been reported that $\mathrm{Mg}^{2+}$ ions play a role in blood clotting competing with $\mathrm{Ca}^{2+}$ ions. Moreover, magnesium has a different and conflicting role on proteins of coagulation cascade and its net action on coagulation is difficult to predict. For this reason we have investigated whether magnesium can change clotting characteristics of plasma and blood. We have found that magnesium increases the clotting time in plasma and in whole blood in a concentration-dependent fashion. Also, blood clotted in the presence of increased concentration of magnesium, has progressively shortened the lysis time of whole blood clots. We postulated that $\mathrm{Mg}^{2+}$ exerts its anticoagulant influence by acting at the stage of prothrombin activation in the blood coagulation cascade competing with calcium needed for thrombin activation. Shortening lysis of whole blood clots can utilize an alternative mechanism. PAI-1 in the presence of thrombin, vitronectin and $\mathrm{Ca}^{2+}$ or $\mathrm{Mg}^{2+}$ is inhibited, causing larger amounts of tPA to remain in the free form. Excessive amounts of tPA activate plasminogen that lyses clots faster. However, further investigations are required to determine the clinical relevance of these observations.
\end{abstract}

Key words: magnesium, anticoagulants.

(Centr Eur J Immunol 2013; 38 (2): 149-153)

\section{Introduction}

Magnesium is one of the most plentiful intracellular cations and is a cofactor in approximately 300 enzymatic reactions. Only less than $1 \%$ of the total amount of $\mathrm{Mg}$ is present in blood [1]. Magnesium salts alone or mixed with other minerals and vitamins are commonly used as dietary supplements. Also, magnesium is infused intra-operatively in a variety of surgeries [2]. Magnesium is considered safe and beneficial [3-6], however there are some reports on its health risk when overdosed [7, 8]. For adults over 30, the recommended daily dose is $420 \mathrm{mg} /$ day for men and $320 \mathrm{mg} /$ day for women. However, Niedworok et al. report- ed that in a group of 949 people they found that the recommended daily dose for magnesium was exceeded by 292 $\mathrm{mg} /$ day (183 women and $109 \mathrm{men}$ ). The authors emphasized that an uncontrolled excessive magnesium intake by both men and women may constitute a health threat [9].

It has been reported that $\mathrm{Mg}^{2+}$ ions play a role in blood clotting competing with $\mathrm{Ca}^{2+}$ ions [3, 10-13]. Anstall et al. reported that small amounts of magnesium added to fresh human plasma prolong the clotting time substantially. They explain this action as a cation antagonism between $\mathrm{Mg}^{2+}$ and $\mathrm{Ca}^{2+}$, both competing for clotting factors. Also, they revealed an interesting fact that in Germany during and shortly after the Second World War, magnesium sulfate was 
widely used as a muscle relaxant and the blood of patients examined post mortem after such treatment was unclottable [14]. Na et al. investigated intra-operative infusion of magnesium sulfate by maintaining magnesium levels at the upper limit of the normal range $(1.58 \mathrm{mmol} / \mathrm{l})$ and found that $\mathrm{Mg}^{2+}$ extends the clotting time [2]. Sekiya et al. reported that not only $\mathrm{Ca}^{2+}$ cations, but also $\mathrm{Mg}^{2+}$ cations stabilize the native conformation of coagulation factor IX and at physiological concentrations significantly amplify the biological activities of this factor. Using dialyzed plasma supplemented with coagulation factors, they showed also that addition of $\mathrm{Mg}^{2+}$ ions augmented the apparent coagulant activity of factor IXa but not factor Xa. Moreover, activation of factor $\mathrm{X}$ by factor IXa in the presence of factor VIIIa, phospholipids, and $\mathrm{Ca}^{2+}$ cations was accelerated by $\mathrm{Mg}^{2+}$ cations. They also observed that clotting of normal plasma induced by factor VIIa was shortened by magnesium as well [10].

In the blood coagulation pathway, calcium activates prothrombin to thrombin that converts fibrinogen to fibrin. Prothrombin is post-translationally altered in a vitamin K-dependent reaction converting glutamic acids to $\gamma$-carboxyglutamic acid (Gla). Gla residues promote the binding of prothrombin to phospholipid bilayers in the presence of $\mathrm{Ca}^{2+}$. Binding different cations produces a structure different from that induced by calcium, nevertheless some cations can bind to phospholipids $[15,16]$. Nelsestuen et al. reported that calcium is required for two distinct steps in prothrombin activation (factor $\mathrm{X}$ and prothrombin-phospholipid binding). The first step was activated by nearly all cations tested $\left(\mathrm{Mg}^{2+}, \mathrm{Ca}^{2+}, \mathrm{Sr}^{2+}, \mathrm{Ba}^{2+}, \mathrm{Mn}^{2+}, \mathrm{Be}^{2+}, \mathrm{Fe}^{2+}, 3+, \mathrm{Zn}^{2+}\right)$. However, the calcium binding sites implicated in the proteinphospholipid complex formation, show superior selectivity for cations required for the protein transition. Only strontium and barium are observed to satisfactorily replace calcium in this role. The others will form a protein-phospholipid complex with a different structure resulting in inhibition of the coagulation reactions [15].

Magnesium has a different and conflicting role on proteins of coagulation cascade and its net action on coagulation is difficult to predict. For this reason, we have investigated whether magnesium can change clotting characteristics of human plasma and blood.

\section{Material and methods}

Lyophilized Specialty Assayed Reference Plasma, Cat. No. 5185 (S.A.R.P., $10 \times 1 \mathrm{ml}$ ) from Helena Laboratories, Beaumont, TX, was prepared from a frozen pool of citrated plasma of healthy donors. S.A.R.P. has normal PT and aPTT clotting times and can be used as reference material for the following parameters: fibrinogen**, factor II*, factor $\mathrm{V}^{* *}$, factor $\mathrm{VII}^{*}$, factor VIII*, factor $\mathrm{IX}^{*}$, factor $\mathrm{X}^{*}$, factor $\mathrm{XI}^{* *}$, ristocetin cofactor*, $\mathrm{vWF}: \mathrm{Ag}^{*}$, factor XII, protein $\mathrm{C}^{*}$, protein $\mathrm{S}-$ total, free (*Standardized to $\mathrm{WHO}$,
**Calibrated against ISTH reference material). Plasma was stored at $4^{\circ} \mathrm{C}$, reconstituted by adding $1 \mathrm{~mL}$ of deionized water and rest for 5 minutes.

Blood was drawn from five healthy subjects ( 3 males and 2 females, aged 47-78) into plain evacuated plastic tubes and immediately placed on ice. Subsequently, $0.3 \mathrm{ml}$ portions of whole blood were pipetted into glass test-tubes (10 $\times 70 \mathrm{~mm}$ ) containing various concentrations of magnesium chloride (Sigma-Aldrich). Afterwards, the test-tubes were incubated at $37^{\circ} \mathrm{C}$ and the time of clotting of blood was recorded with a stop-watch. The clotted blood samples were then further incubated at $37^{\circ} \mathrm{C}$ and times of thrombolysis were observed for up to $24 \mathrm{hrs}$.

Plasma clot formation. In a separate experiment, human citrated plasma (pooled) was dialyzed against phosphate

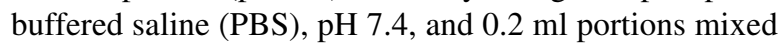
with $20 \mu \mathrm{l}$ of magnesium chloride solutions at various molar concentrations. Next, $20 \mu 1$ of thrombin (100 U/ml; SigmaAldrich) was added to each tube and the clotting time was recorded. Each experiment was done in triplicate and mean value \pm SD was calculated.

Analysis of plasma clot formation with thromboelastography. Thromboelastography allows for the measurement of a global coagulation profile and yields data on the kinetics and dynamics of clot formation and clot lysis in plasma and whole blood [17]. The critical part of this instrument is a pin hanging on a torsion wire and suspended in a cup holding a sample $(360 \mu \mathrm{l})$. This pin oscillates at $6 \mathrm{rpm}$ at a $4^{\circ} 45^{\prime}$ angle at $37^{\circ} \mathrm{C}$. When plasma viscosity changes during clot formation, this pin motion is progressively restrained by the clot and the cup. The strength of the clot determines the degree of the force on the pin. Sodium citrated, reconstituted plasma was used for TEG assays by mixing $1 \mathrm{ml}$ of plasma with $20 \mu \mathrm{l}$ of kaolin (Haemoscope Co., Neils, IL, USA) to which $20 \mu$ of $\mathrm{CaCl}_{2}(0.2 \mathrm{M})$ or/and of $\mathrm{MgCl}_{2}(0.2 \mathrm{M})$ was added. The critical parameters of clotting measured by TEG are as follows: $\mathrm{R}$ is the time from the start of the reaction until a measurable clot is detected, $\mathrm{K}$ is the time from the $R$ point until a certain clot firmness is achieved, An $(\alpha)$ is the maximum angle that represents kinetics of clotting and LY45 (percentage) represents clot lysis 45 min after MA (maximum amplitude) [17-19].

\section{Results and discussion}

Thromboelastography is an established method for measuring plasma or whole blood clotting characteristics and has been evaluated systematically for its role in the detection and management of coagulation problems. We use this method to establish the effect of magnesium on coagulation. Table 1 and Fig. 1 show that magnesium extended $\mathrm{R}$ time significantly in comparison with not treated plasma and differences were statistically significant. Magnesium changes the other parameters of plasma coagulation (increase K, lowers $\alpha$ ) but no statistical significance was 


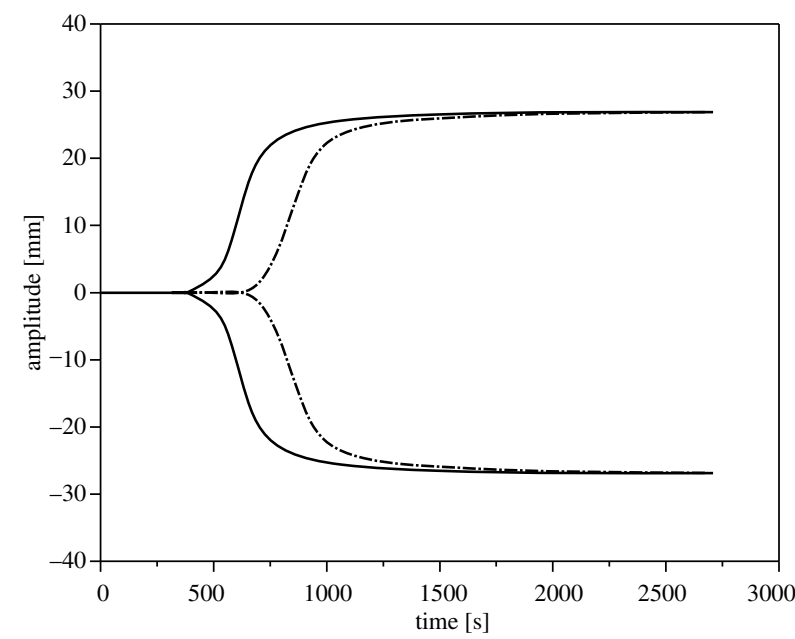

Fig. 1. Example of thromboelastogram of plasma: solid line clotting was induced by addition of $\mathrm{CaCl}_{2}$; dotted line - clotting induced by $\mathrm{CaCl}_{2}$ in the presence of $\mathrm{MgCl}_{2}$. Clotting parameters are practically the same except for a significant increase in $\mathrm{R}$ time in the presence of $\mathrm{Mg}^{2+}$

established. Similar observations were made for whole blood by James et al. [20]. It is important to notice that magnesium changes these parameters to such extent that they are out of normal range. There are no normal ranges established for plasma but by comparison with our previous experiments, R time was well out of control values (not treated) for the majority of the examined samples $(>75)$ [21]. Both $\mathrm{R}$ and $\mathrm{K}$ parameters are a measure of time of initiation of coagulation and these extensions suggest prolonged bleeding in patients. The $\alpha$ angle is a measure of speed of clot formation in the initial phase and its low values could suggest extended bleeding as well. Thrombolysis, as measured by amplitude at 45 minutes, was not affected by magnesium in our study and in the report by James et al. [20]. These are important findings since $\mathrm{Mg}^{2+}$ could inhibit or potentiate the fibrinolytic activity by affecting tissue plasminogen activator activity. Stewart et al. investigated the effect of $\mathrm{Mg}^{2+}$ on tPA and they found that $\mathrm{MgSO}_{4}$ had no effect on tPA induced clot lysis (60 minutes) at up to six times of normal serum concentration [22].

Thromboelastometry is an ideal method to measure dynamics of blood clotting and clot strength. However, it cannot measure clotting parameters longer than $180 \mathrm{~min}$ utes [17, 23, 24]. Therefore, we have also measured plasma and blood clotting using different methods.

Effect of magnesium chloride on spontaneous clotting whole blood and plasma. In the freshly collected blood we have observed that magnesium increased the clotting time in a concentration-dependent fashion. In the highest concentration (10 mM) blood did not clot (Fig. 2). Since prothrombin activation requires calcium ions, it is quite pos-
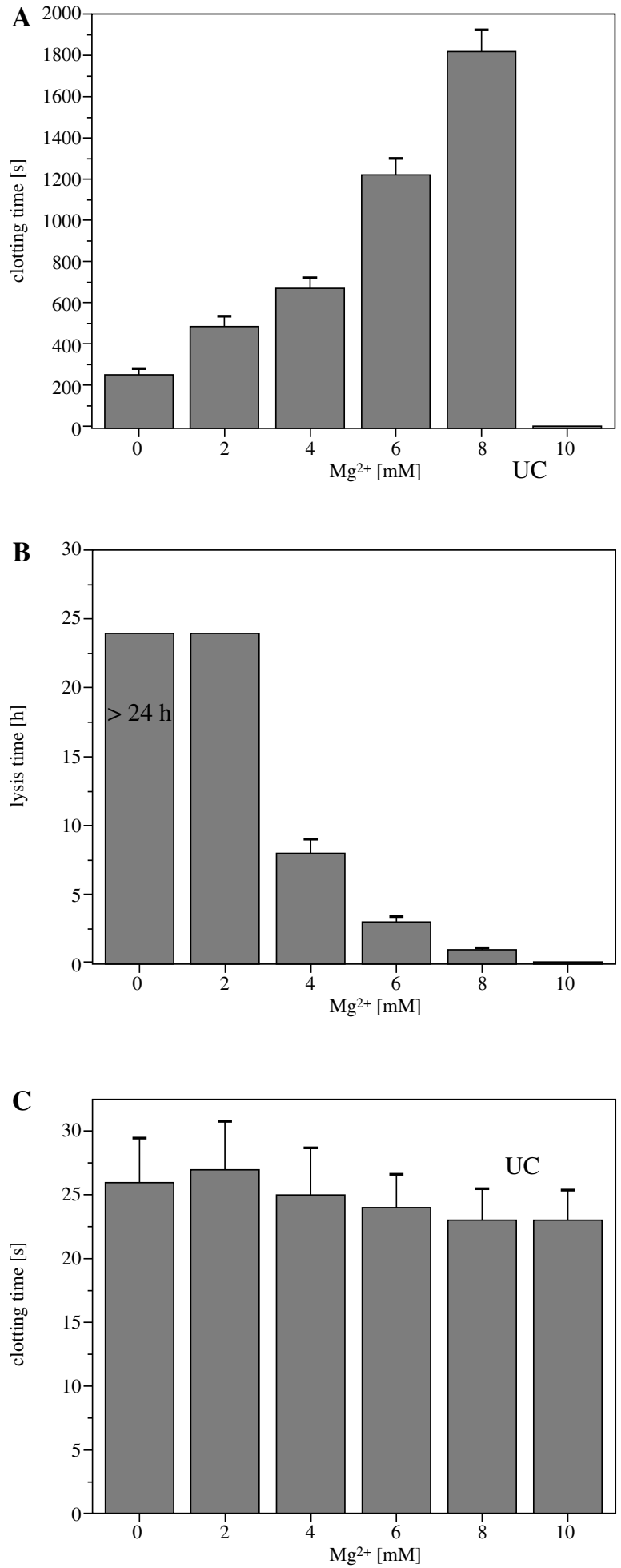

Fig. 2. Effect of magnesium chloride on: A - spontaneous clotting of whole blood; B - thrombolysis of whole blood; C thrombin-induced clotting of human plasma. Values expressed as means (triplicate) $\pm \mathrm{SD}$; UC - unclottable 
Table 1. Selected parameters of blood and plasma clotting by TEG

\begin{tabular}{|c|c|c|c|c|c|}
\hline & $\begin{array}{c}\text { Range in blood } \\
\text { (TEG) }\end{array}$ & Blood control & Blood magnesium & Plasma control & $\begin{array}{c}\text { Plasma } \\
\mathrm{Ca}^{2+}+\mathrm{Mg}^{2+}\end{array}$ \\
\hline $\mathrm{R}[\mathrm{s}]$ & $240-480$ & $438 \pm 72$ & $624 \pm 114$ & $522 \pm 48$ & $720 \pm 12$ \\
\hline $\mathrm{K}[\mathrm{s}]$ & $0-240$ & $198 \pm 234$ & $306 \pm 42$ & $162 \pm 60$ & $222 \pm 60$ \\
\hline$\alpha\left[^{\circ}\right]$ & $47-74$ & $35.6 \pm 6.7$ & $27.5 \pm 5.7$ & $55.1 \pm 9.6$ & $45.4 \pm 0.6$ \\
\hline $\mathrm{MA}[\mathrm{mm}]$ & $54-72$ & $50.2 \pm 4.7$ & $46.5 \pm 2.4$ & $27.0 \pm 3.0$ & $24.8 \pm 1.0$ \\
\hline
\end{tabular}

Normal ranges were reported by: [17, 34, 35]; blood control and blood magnesium by [20].

sible that $\mathrm{Mg}$ competes with $\mathrm{Ca}$ for the binding sites at the prothrombin molecule, thus altering its ability to initiate intrinsic blood coagulation. It is also possible that magnesium may counterbalance the procoagulant effect of free iron that is known to accumulate with age [25]. By contrast, magnesium blood content is decreasing with age, and this may explain why degenerative diseases are age-related [2529] and why hypomagnesemia potentiates the pro-thrombotic consequences of free iron [30]. In view of the fact that magnesium has no effect in dialyzed human plasma clotted with thrombin (Fig. 2C), it has to be concluded that $\mathrm{Mg}$ exerts its anticoagulant influence by acting at the stage of prothrombin activation in the blood coagulation cascade. Therefore, we suggest that magnesium can be used as a safe anticoagulant that does not inhibit extrinsic clotting of blood occurring at the site of vessel wall injury [32, 33].

In addition, we have found that blood clotted in the presence of increased concentration of magnesium has progressively shortened the lysis time of whole blood clots (Fig. 2B). This unexpected finding can be explained by works done by Urano et al. [11-13]. These investigators found that when PAI-1 enriched fibrin clots were formed by increasing concentrations of thrombin $(0.1-1.0 \mathrm{IU} / \mathrm{ml})$ in the presence of calcium, their lysis times became shorter (43.8-13.9). Times of lysis were shortened further by addition of vitronectin (17.0-0.9 h). Using fibrin autography they found that both enzymes interfered in a dose-dependent manner with complex formation between TPA and PAI-1, with large amounts of tPA remaining in the free form. They concluded that this mechanism plays a role in the enhancement of fibrinolysis [11-13]. It is plausible that magnesium activates this mechanism similarly as calcium does.

Jahnen-Dechent W and Ketteler reported that moderate hypermagnesemia ( $>1.6 \mathrm{mmol} / \mathrm{l}$ in serum) is associated with hypotension, cutaneous flushing, nausea and vomiting. At higher concentrations, magnesium might lead to neuromuscular dysfunction, ranging from drowsiness to respiratory depression, hypotonia, areflexia and coma in severe cases. They also reported cardiac effects of hypermagnesemia including bradycardia, complete heart block, atrial fibrillation but not abnormalities of blood clotting or increased susceptibility to hemorrhage as a complication of magnesium therapy [31]. Contrary to that, Besselaar et al. found that even a small contamination of blood collecting tubes with magnesium can significantly change blood coagulation parameters $[32,33]$. It must be stressed that in vitro and in vivo findings seem to be in conflict with each other. However, hypermagnesemia is a relatively rare condition and it is possible that this coagulopathy was simply overlooked.

In conclusion, magnesium infusion or consumption can attenuate an intrinsic coagulation pathway affecting hemostatic propensity of blood. Hence, further investigations are required to determine the clinical relevance of this observation.

The authors declare no conflict of interest.

\section{References}

1. Elin RJ (1994): Magnesium: the fifth but forgotten electrolyte. Am J Clin Pathol 102: 616-622.

2. Na HS, Chung YH, Hwang JW, Do SH (2012): Effects of magnesium sulphate on postoperative coagulation, measured by rotational thromboelastometry $(\operatorname{ROTEM}(\mathrm{R}))$. Anaesthesia 67: 862-869.

3. Choi JH, Lee J, Park CM (2005): Magnesium therapy improves thromboelastographic findings before liver transplantation: a preliminary study. Can J Anaesth 52: 156-159.

4. Farvid MS, Homayouni F, Amiri Z, Adelmanesh F (2011): Improving neuropathy scores in type 2 diabetic patients using micronutrients supplementation. Diabetes Res Clin Pract 93: 86-94.

5. Mathers TW, Beckstrand RL (2009): Oral magnesium supplementation in adults with coronary heart disease or coronary heart disease risk. J Am Acad Nurse Pract 21: 651-657.

6. Pan HC, Sheu ML, Su HL, et al. (2011): Magnesium supplement promotes sciatic nerve regeneration and down-regulates inflammatory response. Magnes Res 24: 54-70.

7. Bailey RL, Fulgoni VL $3^{\text {rd }}$, Keast DR, Dwyer JT (2011): Dietary supplement use is associated with higher intakes of minerals from food sources. Am J Clin Nutr 94: 1376-1381.

8. Gaby AR (2010): Nutritional treatments for acute myocardial infarction. Altern Med Rev 15: 113-123.

9. Niedworok E, Muc-Wierzgon M, Nowakowska-Zajdel E, et al. (2011): Magnesium content in daily food portions and the influence of supplementation. Int J Immunopathol Pharmacol 24: 975-981. 
10. Sekiya F, Yoshida M, Yamashita T, Morita T (1996): Magnesium (II) is a crucial constituent of the blood coagulation cascade. Potentiation of coagulant activities of factor IX by $\mathrm{Mg}^{2+}$ ions. J Biol Chem 271: 8541-8544.

11. Urano T, Ihara H, Suzuki Y, et al. (2000): Coagulation-associated enhancement of fibrinolytic activity via a neutralization of PAI-1 activity. Semin Thromb Hemost 26: 39-42.

12. Urano T, Ihara H, Takada Y, et al. (1996): The inhibition of human factor Xa by plasminogen activator inhibitor type 1 in the presence of calcium ion, and its enhancement by heparin and vitronectin. Biochim Biophys Acta 1298: 199-208.

13. Urano T, Nagai N, Matsuura M, et al. (1998): Human thrombin and calcium bound factor Xa significantly shorten tPAinduced fibrin clot lysis time via neutralization of plasminogen activator inhibitor type 1 activity. Thromb Haemost 80: 161-166.

14. Anstall HB, Hayward GH, Huntsman RG, et al. (1959): The effect of magnesium on blood coagulation in human subjects. Lancet 1: 814-815.

15. Nelsestuen GL, Broderius M, Martin G (1976): Role of gamma-carboxyglutamic acid. Cation specificity of prothrombin and factor X-phospholipid binding. J Biol Chem 251: 68866893.

16. Soriano-Garcia M, Padmanabhan K, de Vos AM, Tulinsky A (1992): The $\mathrm{Ca}^{2+}$ ion and membrane binding structure of the Gla domain of Ca-prothrombin fragment 1. Biochemistry $31: 2554-2566$.

17. Evans PA, Hawkins K, Lawrence M, et al. (2008): Studies of whole blood coagulation by oscillatory shear, thromboelastography and free oscillation rheometry. Clin Hemorheol Microcirc 38: 267-277.

18. Jankun J, Keck R, Selman SH, Skrzypczak-Jankun E (2010): Systemic or topical application of plasminogen activator inhibitor with extended half-life (VLHL PAI-1) reduces bleeding time and total blood loss. Int J Mol Med 26: 501-504.

19. Jankun J, Selman SH, Keck RW, et al. (2010): Very long halflife plasminogen activator inhibitor type 1 reduces bleeding in a mouse model. BJU Int 105: 1469-1476.

20. James MF, Neil G (1995): Effect of magnesium on coagulation as measured by thrombelastography. Br J Anaesth 74: 92-94.

21. Jankun J, Skotnicka M, Łysiak-Szydłowska W, et al. (2011): Diverse inhibition of plasminogen activator inhibitor type 1 by theaflavins of black tea. Int J Mol Med 27: 525-529.

22. Stewart D, Marder VJ, Starkman S, Saver JL (2006): Magnesium sulfate neither potentiates nor inhibits tissue plasminogen activator-induced thrombolysis. J Thromb Haemost 4: 1575-1579.

23. Afshari A, Wikkelsø A, Brok J, et al. (2011): Thrombelastography (TEG) or thromboelastometry (ROTEM) to monitor haemotherapy versus usual care in patients with massive transfusion. Cochrane Database Syst Rev: CD007871.

24. Jackson GN, Ashpole KJ, Yentis SM (2009): The TEG vs the ROTEM thromboelastography/thromboelastometry systems. Anaesthesia 64: 212-215.

25. Barbagallo M, Belvedere M, Dominguez LJ (2009): Magnesium homeostasis and aging. Magnes Res 22: 235-246.

26. Houston M (2011): The role of magnesium in hypertension and cardiovascular disease. J Clin Hypertens (Greenwich) 13: 843-847.

27. Limaye CS, Londhey VA, Nadkart MY, Borges NE (2011): Hypomagnesemia in critically ill medical patients. J Assoc Physicians India 59: 19-22.

28. Mazur A, Maier JA, Rock E, et al. (2007): Magnesium and the inflammatory response: potential physiopathological implications. Arch Biochem Biophys 458: 48-56.
29. Reffelmann T, Ittermann T, Dörr M, et al. (2011): Low serum magnesium concentrations predict cardiovascular and all-cause mortality. Atherosclerosis 219: 280-284.

30. Lipinski B, Pretorius E (2012): Novel pathway of ironinduced blood coagulation: implications for diabetes mellitus and its complications. Pol Arch Med Wewn 122: 115-122.

31. Jahnen-Dechent W, Ketteler M (2012): Magnesium basics. Clin Kidney J 5 Suppl 1: 3-14.

32. van den Besselaar AM, Rutten WP, Witteveen E (2005): Effect of magnesium contamination in evacuated blood collection tubes on the prothrombin time test and ISI calibration using recombinant human thromboplastin and different types of coagulometer. Thromb Res 115: 239-244.

33. van den Besselaar AM, van Dam W, Sturk A, Bertina RM (2001): Prothrombin time ratio is reduced by magnesium contamination in evacuated blood collection tubes. Thromb Haemost 85: 647-650.

34. Carroll RC, Craft RM, Chavez JJ, et al. (2008): Measurement of functional fibrinogen levels using the thrombelastograph. J Clin Anesth 20: 186-190.

35. Gallimore MJ, Harris SL, Tappenden KA, et al. (2005): Urokinase induced fibrinolysis in thromboelastography: a model for studying fibrinolysis and coagulation in whole blood. J Thromb Haemost 3: 2506-2513. 